\title{
Evidence for non-infiltrative cardiomyopathy in acute leukaemia and lymphoma A clinical and echocardiographic study
}

\author{
M. AFZAL MIR
}

From the University Department of Cardiology, Manchester Royal Infirmary, Manchester

SUMMARY Left ventricular function was assessed with echocardiography in 27 normal subjects and in 38 patients with acute leukaemia and lymphoma. Eighteen patients in the leukaemia-lymphoma group $(47 \%)$ had left ventricular dysfunction before chemotherapy as suggested by a significantly $(P<0.001)$ abnormal end-systolic dimension and a low fractional shortening. Cardiac failure developed in 12 patients $(32 \%): 3$ patients with preleukaemia, 3 with acute myeloid leukaemia, and 1 with Hodgkin's disease had heart failure before cytotoxic therapy and 5 others developed it within 3 to 24 weeks after 75 to $920 \mathrm{mg}$ daunorubicin. Cardiac failure in 5 of the 7 pre-daunorubicin cases was well controlled while all the 5 patients who developed left ventricular failure after daunorubicin died. In 3 of these the heart failure was the only cause of death. Necropsy in 4 patients showed no leukaemic infiltration of the myocardium. Sequential echocardiograms showed a deterioration in left ventricular function during the first 6 months and a steady improvement in patients who lived longer than 9 months.

This study shows that 47 per cent of patients with acute leukaemia and lymphoma have non-infiltrative cardiomyopathy which is unrelated to drugs, and a significant proportion of these develop heart failure.This cardiomyopathy does not appear to be reversible though patients who survive longer than 9 months show some improvement in their left ventricular function. Cardiac failure also develops in some patients with normal left ventricular function. This and the deterioration in left ventricular function during the first 6 months in leukaemic patients may be caused by daunorubicin which is a potent antileukaemic drug.

Cardiac failure is a well-known complication in acute myeloid leukaemia. Various investigators (Bernard et al., 1967; Tan et al., 1967; Malpas and Scott, 1968; Bonadonna and Monfardini, 1969; Marmont et al., 1969; Halazun et al., 1974) have attributed this to the anthracycline group (daunorubicin and adriamycin) of antileukaemic drugs, but no one has studied left ventricular function in leukaemic patients before giving these drugs. At the Manchester Royal Infirmary we have seen cardiac failure in some young leukaemic patients who had received no cytotoxic drugs and who had no past history of heart disease. This experience suggested that patients with acute myeloid leukaemia probably have poor left ventricular function, and this hypothesis was tested by assessing left ventricular function in patients with acute leukaemia and lymphoma before and after chemotherapy.

${ }^{1}$ Department of Medicine, University Hospital of Wales, Heath Park, Cardiff CF4 4XW.

Received for publication 18 July 1977

\section{Patients and methods}

\section{CLINICAL GROUPS}

Thirty-eight unselected patients with acute leukaemia and lymphoma, 6 patients with anaemia, and 27 normal subjects were studied. The leukaemia-lymphoma group consisted of 15 patients with acute myeloid leukaemia; 10 with acute myelomonocytic leukaemia; 5 with acute lymphoblastic leukaemia; 4 with preleukaemia (see below); 2 with lymphoma, 1 with Hodgkin's disease, and 1 with acute monocytic leukaemia (Table 1). The term preleukaemia is applied to the refractory anaemia that is not identifiable as one of the recognised forms. Patients with this condition develop neutropenia and thrombocytopenia at some stage of the disease; their circulating blood shows some immature cells and morphological abnormalities in erythrocytes; and their bone marrow shows disordered maturation in all three cell lines and a slightly increased number of myeloblasts (Linman 
Table 1 Pre-daunorubicin clinical and echocardiographic data in 38 patients with acute leukaemia and lymphoma

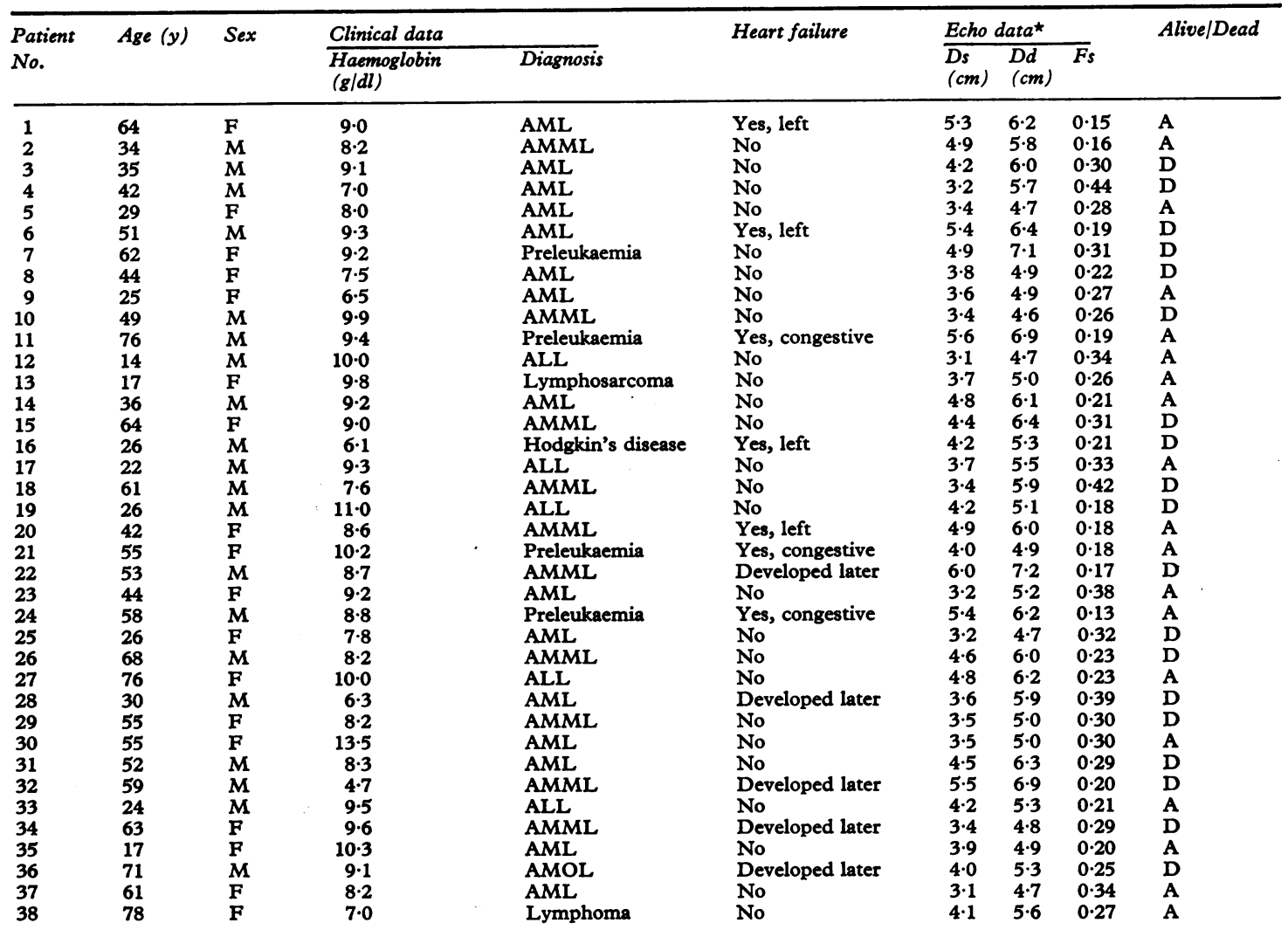

AML, acute myeloblastic leukaemia; AMML, acute myelomonocytic leukaemia; ALL, acute lymphoblastic leukaemia; AMOL, acute monocytic leukaemia.

« See Table 2 for abbreviations.

Table 2 Echocardiographic data in normal, leukaemic, and anaemic patients

\begin{tabular}{|c|c|c|c|c|c|}
\hline \multirow[t]{2}{*}{ Groups } & & \multirow[t]{2}{*}{ Age (y) } & \multicolumn{3}{|c|}{ Echo data } \\
\hline & & & $D s(\mathrm{~cm})$ & $D d(\mathrm{~cm})$ & $F_{s}$ \\
\hline $\begin{array}{l}\text { Normal } n=27 \\
\text { Acute leukaemia and lymphoma } n=38 \\
\text { Mean haemoglobin } 8.7 \mathrm{~g} / \mathrm{dl} \\
\text { Anaemia } \mathrm{n}=6 \\
\text { Mean haemoblobin } 7 \cdot 1 \mathrm{~g} / \mathrm{dl}\end{array}$ & $\begin{array}{l}\text { Mean } \\
\text { SE } \\
\text { Mean } \\
\text { SE } \\
\text { P } \\
\text { Mean } \\
\text { SE }\end{array}$ & $\begin{array}{c}43 \\
3 \\
48 \\
3 \\
\text { NS } \\
36 \\
7\end{array}$ & $\begin{array}{l}3 \cdot 0 \\
0.13 \\
4.2 \\
0.13 \\
<0.001 \\
3.5 \\
0.3\end{array}$ & $\begin{array}{l}5.0 \\
0.08 \\
5.6 \\
0.12 \\
<0.001 \\
\quad 5.7 \\
0.4\end{array}$ & $\begin{array}{l}0.37 \\
0.01 \\
0.26 \\
0.01 \\
<0.0005 \\
0.40 \\
0.03\end{array}$ \\
\hline
\end{tabular}

Ds, end-systolic dimension; Dd, end-diastolic dimension; Fs, fractional shortening (Dd - Ds/Dd); NS, not significant.

and Saarni, 1974). Diagnosis was made by standard haematological methods. The clinical details of patients with acute leukaemia and lymphoma are presented in Table 1.

The anaemic group consisted of 3 patients with iron deficiency anaemia, 1 with pernicious anaemia, 1 with gastrointestinal blood loss, and 1 with aplastic anaemia. Their haemoglobin ranged from $5 \cdot 4$ to $9 \cdot 1 \mathrm{~g} / \mathrm{dl}$, with a mean of $7 \cdot 1 \mathrm{~g} / \mathrm{dl}$. Their age ranged from 15 to 64 with a mean of 36 years (Table 2).

Normal data were collected from 24 volunteers from the medical, nursing, and technical staff and from 3 non-cardiac patients. Their age ranged from 20 to 78 years, with a mean of 43 years. 
Patients with a past history of hypertension and ischaemic heart disease were excluded. All patients had a clinical examination and routine investigations. Therapeutic decisions were made by the haematological team under whose care the leukaemic patients were admitted to hospital.

\section{ECHOCARDIOGRAPHY}

Left ventricular function was studied by echocardiography (Cooper et al., 1972; Quinones et al., 1974; Feigenbaum, 1975). Left ventricular echograms were taken in all patients in the leukaemialymphoma group, before cytotoxic therapy, 2 to 4 weeks after chemotherapy, and thereafter every 3 months. Echocardiograms were recorded with an Ekoline 20A ultrasonoscope. The subjects were examined in the supine position after a rest period of at least 15 minutes. The transducer was placed in the left third or fourth intercostal space just lateral to the left sternal edge and the mitral valve was located. The transducer was then directed laterally and posteroinferiorly until the posterior left ventricular wall, the ventricular septum, and a part of the mitral valve apparatus were visible in the same view. Only the good quality echocardiograms, where the echoes from the endocardial surface of the septum and posterior left ventricular wall were clearly visible, were accepted. Eight patients initially studied had to be excluded because of unsatisfactory echo records.

The left ventricular end-diastolic (Dd) and endsystolic (Ds) dimensions were measured with the aid of the simultaneously recorded calibration scale (see Fig. 1). End-diastolic dimensions were drawn through the $S$ wave of the electrocardiogram, and end-systolic measurements were made at the points of least separation between the left septal (before the anterior dip) and the posterior endocardial echoes.

Fractional shortening (Fs), the systolic shortening of the end-diastolic dimension, was calculated from the formula

$$
F s=\frac{D d-D s}{D d}
$$

During the early stages of this study, echocardiographic examination was repeated in 6 normal subjects. The left ventricular dimensions varied only slightly ( $<3 \mathrm{~mm}$ ) from month to month if all the conditions (i.e. examiner, posture, rest period, etc.) were the same. With this knowledge in mind, sequential echocardiograms were recorded in leukaemic patients, and the change in Ds as an index of left ventricular performance was thereby monitored.

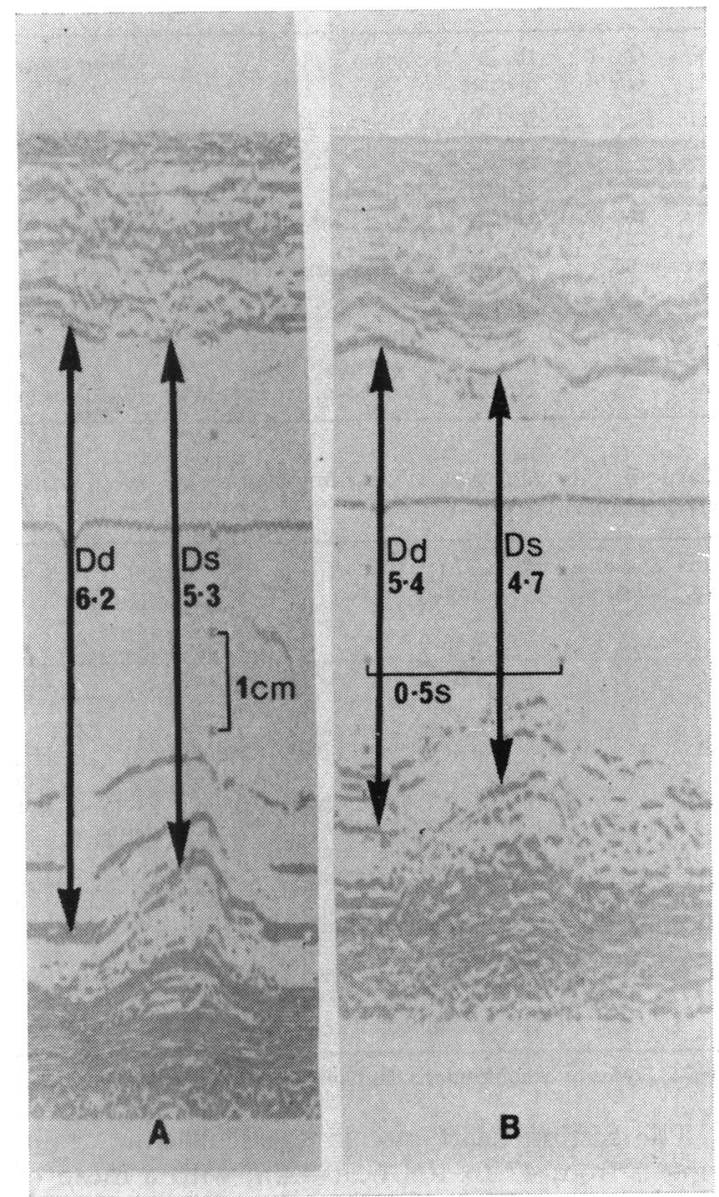

Fig. 1 Left ventricular echograms of case 1 before daunorubicin $(A)$ and 2 years later $(B)$. Both the end-systolic ( $D s)$ and end-diastolic ( $D d$ d) dimensions are abnormally large before treatment and show a decrease 2 years later.

\section{Results}

\section{ECHOCARDIOGRAPHIC DATA}

Table 1 shows clinical and echocardiographic data in 38 patients with acute leukaemia and lymphoma before they had been given chemotherapy. Eighteen patients $(47 \%)$ in this group had fractional shortening below 0.26 which is the lower limit for normal in our laboratory. In the leukaemia-lymphoma group, 3 of the 4 patients with preleukaemia $(75 \%)$, 5 of the 10 patients with acute myelomonocytic $(50 \%)$, and 3 of the 5 patients with acute lymphoblastic leukaemia $(60 \%)$ had low fractional shortening, while only 5 of the $15(33 \%)$ patients with acute myeloblastic leukaemia had low fractional shortening (Table 1). 
Table 3 Clinical details of 7 patients with pre-daunorubicin heart failure

\begin{tabular}{|c|c|c|c|c|c|c|}
\hline $\begin{array}{l}\text { Case } \\
\text { No. }\end{array}$ & $\begin{array}{l}\text { Heart } \\
\text { rate/min }\end{array}$ & $\begin{array}{l}\text { Blood } \\
\text { pressure } \\
\text { monHg }\end{array}$ & Clinical signs & Chest x-ray & $E C G$ & Therapy \\
\hline 1 & 98 & $110 / 80$ & Gallop, basal crackles & Upper lobe vessels dilated & $\begin{array}{l}\text { Low voltage biatrial overload, } \\
\text { partial LBBB }\end{array}$ & None \\
\hline $\begin{array}{r}6 \\
11\end{array}$ & $\begin{array}{r}90 \\
100\end{array}$ & $\begin{array}{l}110 / 70 \\
110 / 70\end{array}$ & $\begin{array}{l}\text { Gallop } \\
\text { Gallop, ankle oedema } \\
\text { JVP } \uparrow\end{array}$ & $\begin{array}{l}\text { Small left pleural effusion } \\
\text { Cardiomegaly }\end{array}$ & $\begin{array}{l}\text { Normal } \\
\text { Low voltage RBBB }\end{array}$ & $\begin{array}{l}\text { Busulphan, allopurinol } \\
\text { Thyroxine }\end{array}$ \\
\hline $\begin{array}{l}16 \\
20\end{array}$ & $\begin{array}{l}65 \\
74\end{array}$ & $\begin{array}{l}120 / 80 \\
130 / 70\end{array}$ & $\begin{array}{l}\text { Gallop, basal crackles } \\
\text { Basal crackles }\end{array}$ & $\begin{array}{l}\text { Stasis lines }+ \\
\text { Upper lobe vessels dilated, } \\
\text { stasis lines }+\end{array}$ & $\begin{array}{l}\text { Inverted } T \text { wave in V1-V3 } \\
\text { ST- } T \text { changes }\end{array}$ & $\begin{array}{l}\text { None } \\
\text { Ferrous sulphate }\end{array}$ \\
\hline 21 & 90 & $120 / 70$ & $\begin{array}{l}\text { Gallop, dependent } \\
\text { oedema, JVP } \uparrow\end{array}$ & Cardiomegaly & Low voltage $S T-T$ changes & Pyridoxine, folic acid \\
\hline 24 & 88 & $110 / 70$ & Dependent oedema, JVP $\uparrow$ & Cardiomegaly & ST-T changes & Lanoxin, frusemide \\
\hline
\end{tabular}

Table 4 Clinical and echocardiographic data of 5 patients with acute leukaemia who developed heart failure after daunorubicin

\begin{tabular}{|c|c|c|c|c|c|c|c|c|c|}
\hline \multirow{2}{*}{$\begin{array}{l}\text { Case } \\
\text { No. }\end{array}$} & \multirow{2}{*}{$\begin{array}{l}\text { Duration between } \\
\text { diagnosis and } \\
\text { failure }(w)\end{array}$} & \multirow{2}{*}{$\begin{array}{l}\text { Therapy before } \\
\text { failure }\end{array}$} & \multirow[t]{2}{*}{ Clinical signs } & \multirow[t]{2}{*}{ Chest x-ray film } & \multirow[t]{2}{*}{$E C G$} & \multicolumn{3}{|c|}{ Echo data } & \multirow{2}{*}{$\begin{array}{l}\text { Leukaemia } \\
\text { status }\end{array}$} \\
\hline & & & & & & $\begin{array}{l}\text { Ds } \\
(\mathrm{cm})\end{array}$ & $\begin{array}{l}D d \\
(\mathrm{~cm})\end{array}$ & Fs & \\
\hline 22 & 12 & $\begin{array}{l}\text { DR } 920 \text { mg, Ara-C, } \\
\text { gentamicin, } \\
\text { cephaloridine }\end{array}$ & Gallop & Pulmonary oedema & ST-T changes & $6 \cdot 8$ & $8 \cdot 0$ & $0 \cdot 15$ & Remission \\
\hline 28 & 4 & DR 200 mg, Ara-C & $\begin{array}{l}\text { Gallop, basal } \\
\text { crackles }\end{array}$ & $\begin{array}{l}\text { Upper lobe vessels } \\
\text { dilated }\end{array}$ & Partial LBBB & 3.9 & $5 \cdot 0$ & 0.22 & No remission \\
\hline 32 & 24 & $\begin{array}{l}\text { DR } 725 \text { mg, Ara-C, } \\
\text { gentamicin, } \\
\text { cephaloridine }\end{array}$ & $\begin{array}{l}\text { Gallop, JVP } \uparrow, \\
\text { ankle oedema }\end{array}$ & $\begin{array}{l}\text { Cardiomegaly, } \\
\text { stasis lines + }\end{array}$ & Normal & $5 \cdot 8$ & $6 \cdot 5$ & 0.11 & Relapse \\
\hline 34 & 12 & $\begin{array}{l}\text { DR } 500 \text { mg, Ara-C, } \\
\text { gentamicin, } \\
\text { cephaloridine, } \\
\text { ampicillin }\end{array}$ & $\begin{array}{l}\text { Gallop, basal } \\
\text { crackles }\end{array}$ & $\begin{array}{l}\text { Dextrocardia, } \\
\text { stasis lines }+\end{array}$ & Ventricular ectopics & 3.9 & $5 \cdot 0$ & 0.22 & Remission \\
\hline 36 & 3 & $\begin{array}{l}\text { DR } 70 \text { mg, Ara-C, } \\
\text { 6-thioguanine, } \\
\text { ampicillin }\end{array}$ & Gallop, JVP $\uparrow$ & Pulmonary oedema & ST-T changes & $4 \cdot 3$ & $5 \cdot 1$ & $0 \cdot 16$ & No remission \\
\hline
\end{tabular}

Ara-C, cytosine arabinoside; DR, daunorubicin.

The resting heart rate in the leukaemic group ranged from 47 to 108 beats/min, with a mean of $84 \pm 12$ (SEM) beats/min. In the normal group the mean heart rate was $68 \pm 14$ beats $/ \mathrm{min}$, with a range of 44 to 103 beats $/ \mathrm{min}$. In the 6 anaemic patients, the minimum resting heart rate was 59 and the maximum was 110 beats $/ \mathrm{min}$, with a mean of $80^{\prime} \pm 17$ beats $/ \mathrm{min}$.

The left ventricular cavity end-systolic (Ds) and end-diastolic (Dd) dimensions were significantly $(P<0.001)$ greater before chemotherapy ${ }^{1}$ in patients with acute leukaemia and lymphoma than in normal subjects (Table 2). The mean Dd in the leukaemia-lymphoma group was approximately the same as in patients with non-neoplastic anaemia, but the mean Ds in leukaemic patients $(4.2 \mathrm{~cm}$ as compared with $3.5 \mathrm{~cm}$ ) was much greater though statistical significance was not achieved $(P<0.10$ $>0.05$ ). Fractional shortening in normal subjects ranged from 0.29 to 0.51 , with a mean of $0.37 \pm 0.01$ (SEM). As compared with the normal, the mean fractional shortening in the leukaemia-lymphoma group was $0.26 \pm 0.01$. The difference was highly ${ }^{1}$ Case 6 had received busulphan for 3 days in another hospital. significant $(P<0.0005)$.

\section{CARDIAC FAILURE}

Of the 18 patients with low fractional shortening, 3 had congestive cardiac failure and 4 others had evidence of left ventricular failure on first presentation before daunorubicin (Tables 1 and 3). All the 3 patients with congestive heart failure had preleukaemia. Five other patients developed cardiac failure within 3 to 24 weeks after daunorubicin (Table 4). Two of these (cases 28 and 34) had normal left ventricular echograms when they were first examined (Table 1). Cases 22 and 34 had achieved clinical and haematological remission when they developed left ventricular failure.

The cardiac failure in 3 preleukaemic patients was adequately controlled with digitalis and diuretics. These patients have been maintained on antifailure therapy for 20 to 76 weeks (Table 5). Similarly, 2 of the 4 patients (cases 1 and 20) with pre-daunorubicin heart failure have remained reasonably well, though case 1 went through a phase of gross congestive failure when she stopped antifailure treatment (see case records). The re- 
Table 5 Results of sequential left ventricular echographic studies in 22 patients in leukaemia-lymphoma group

\begin{tabular}{lllll}
\hline $\begin{array}{l}\text { Duration of } \\
\text { follow-up } \\
(m)\end{array}$ & $\begin{array}{l}\text { No. } \\
\text { improved }\end{array}$ & $\begin{array}{l}\text { No. } \\
\text { deteriorated }\end{array}$ & $\begin{array}{l}\text { No. showing } \\
\text { no change }\end{array}$ & Total studied \\
\hline 3 & 3 & 15 & 4 & 22 \\
6 & 2 & 10 & 3 & 15 \\
12 & 5 & 3 & 1 & 9 \\
18 & 3 & None & 2 & 5 \\
24 & None & 2 & None & 2 \\
\hline
\end{tabular}

$\star_{\text {Rise in }} \mathrm{Fs}(>0.02)$.

tFall in $\mathrm{F}_{8}(>0.02)$.

maining 2 patients from this group (cases 6 and 16), and all the 5 patients who developed heart failure later in the course of their illness, died. The heart failure was the only cause of death in 3 patients (cases 22, 34, and 36); 2 of these (cases 22 and 34) were in clinical and haematological remission at the time of their death.

\section{SEQUENTIAL STUDIES}

No further data were obtained in 9 patients: 5 of these (cases 3, 4, 10, 18, and 29) died within 2 weeks and in 4 others (cases 15, 26, 27, and 38) echocardiograms were technically unsatisfactory. Most of the patients who survived beyond 3 months showed either no change or a fall in Dd and an increase in Ds, with the consequent fall in fractional shortening. As shown in Table 5, 22 patients had echocardiograms at the end of 3 months and fractional shortening fell in 15. Three of these (cases 7, 22, and 34) died. Fifteen patients were followed up for 6 months and fractional shortening fell in 10 of these (cases 1, 2, 5, 8, 11, 12, 25, 32, 35, and 37); in 2 patients (cases 13 and 19) the fractional shortening increased and there was no change in the remaining 3 (cases 16,21 , and 33). The Ds tended to decrease in patients who survived for more than 9 months with the result that their fractional shortening improved. Nine patients (cases 1, 2, 5, 11, 19, 21, 33, 35, and 37) had left ventricular echograms at 12 months and 5 of these (cases 1,2,11,19, and 33) showed an improved fractional shortening. The latest clinical and echocardiographic data of 19 surviving patients are shown in Table 6. Sequential echocardiograms showed a reduction in the intraventricular dimensions but the fractional shortening remained low (Fig. 1) in most patients.

\section{NECROPSY}

Nineteen patients died during the course of this study. A necropsy examination was performed in 7 patients (cases $7,8,15,22,28,34$, and 36), 4 of whom had died with heart failure (see Table 1). No evidence of myocardial infarction was seen in these patients and a microscopical examination failed to show any leukaemic deposits in their hearts.

\section{Illustrative case records}

\section{CASE 1}

This 64-year-old woman was referred with a 4month history of tiredness and breathlessness. She had a haemoglobin level of $9 \mathrm{~g} / \mathrm{dl}$, a leucocyte count of $12 \times 10^{9} / 1$ (blasts $60 \%$ ), and a platelet count of $3 \times 10^{10} / 1$. A marrow aspirate was hypercellular and contained an abundance of myeloblasts. Her pulse rate was $98 / \mathrm{min}$ and her brachial arterial pressure was $110 / 80 \mathrm{mmHg}$. A third heart sound gallop was heard and inspiratory crackles were heard over both lung bases.

Her cardiogram showed low voltage QRS complexes, biatrial overload, and partial left bundlebranch block, and a chest $x$-ray film showed the heart size at the upper limit for normal and upper lobe vessel distension. The echocardiogram suggested poor left ventricular contractility: the enddiastolic dimension (Dd) was large, the endsystolic dimension (Ds) was abnormally large, and fractional shortening (Fs) - the change in Dd during systole relative to Dd-was low (Fig. 1A). A diagnosis of acute myeloblastic leukaemia and left ventricular failure was made and treatment with digitalis and diuretics was started. She improved and her orthopnoea regressed after a week. Chemotherapy with daunorubicin $120 \mathrm{mg}$ and cytosine arabinoside $150 \mathrm{mg}$ according to the sixth MRC trial for acute myeloid leukaemia was started. She was given 7 courses (daunorubicin $820 \mathrm{mg}$ ), and 4 months later a haematological remission was achieved.

She remained in good health and free from heart failure over the next 7 months, but her echocardiogram showed a slight deterioration (Ds 5.3, Dd 6.0, Fs 0.12 ). Unfortunately, she discontinued digitalis and frusemide and was admitted in frank congestive cardiac failure with gross oedema, bilateral pleural effusion, and cardiomegaly. Her echocardiogram showed Ds $5.6 \mathrm{~cm}$, Dd $6.1 \mathrm{~cm}$, and Fs 0.08 . Her blood count and bone marrow indicated that the leukaemia had not relapsed. Treatment with massive doses of frusemide and lanoxin controlled her cardiac failure: the cardiomegaly regressed as did the pleural effusion. She was discharged from the hospital six weeks later, with only a slight ankle oedema.

Her leukaemia relapsed two months later and she was admitted for further chemotherapy. After one course of daunorubicin (100 $\mathrm{mg}$ ) and cytosine arabinoside, remission was induced with a com- 
Table 6 Clinical and echocardiographic data of 19 surviving patients with acute leukaemia and lymphoma

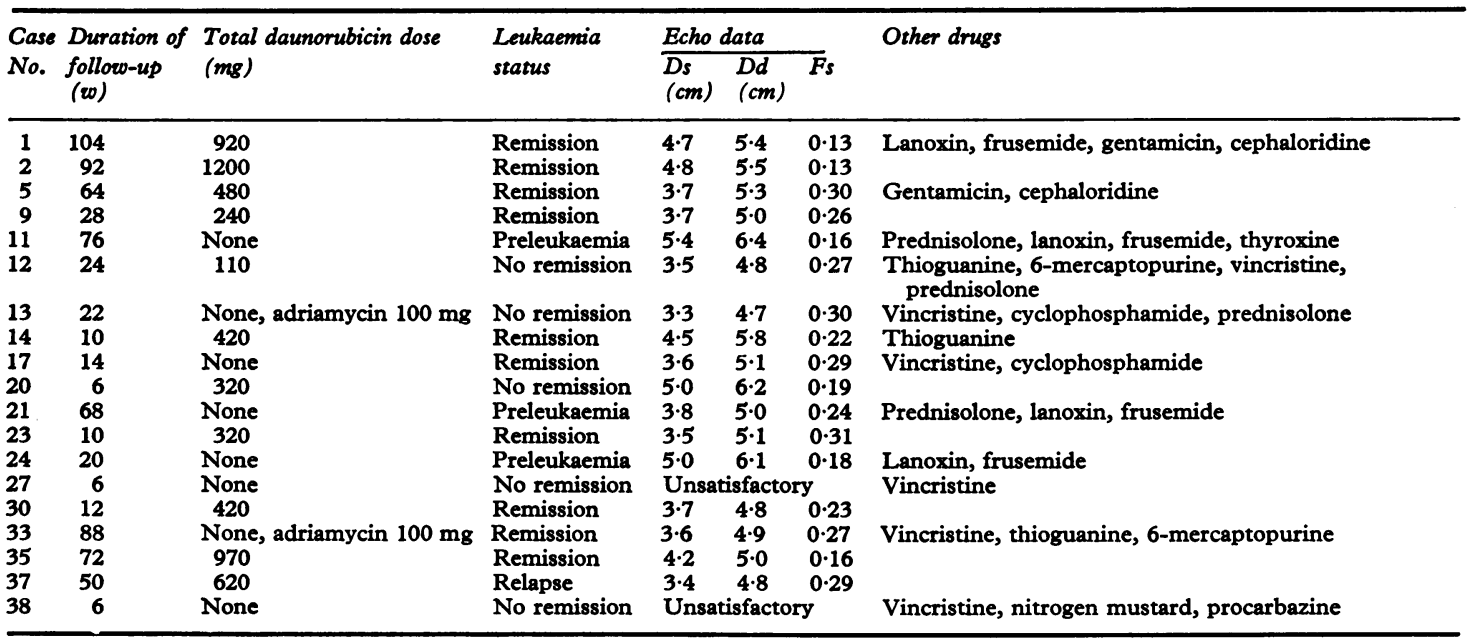

bination of vincristine, cytosine arabinoside, prednisolone, and cyclophosphamide. She has remained in remission for 10 months without any cytotoxic therapy. Her exercise tolerance is poor but she can walk, do some lighter jobs at home, and even carry small packages. She continues to take lanoxin and frusemide daily. Her chest $x$-ray shows cardiomegaly. Her echocardiogram (Fig. 1B) shows decrease in left ventricular dimensions but no improvement in contractility as compared with the one recorded two years earlier at diagnosis (Fig. 1A).

\section{CASE 6}

This 51-year-old man was referred from another hospital where he had been investigated for persistent headaches and a routine blood test had shown a platelet count of $1.3 \times 10^{12} / 1$. Before his transfer he had been given busulphan and allopurinol.

On admission he had orthopnoea, and basal crackles. His left ventricular echogram showed poor left ventricular function (Fig. 2A). A marrow aspirate and trephine biopsy showed features of acute megakaryocytic leukaemia. Treatment was started with cytosine arabinoside and thioguanine. After 3 courses his bone marrow showed an increased number of myeloblasts. His echocardiogram showed a further deterioration in left ventricular function ( $F s=0 \cdot 11$ ) (Fig. 2B). He developed a systemic fungal infection and died. Permission for necropsy was refused.

\section{CASE 11}

This 76-year-old pharmacist was investigated by a general physician for fatigue and cold intolerance. He was found to have a mild hypothyroid state but

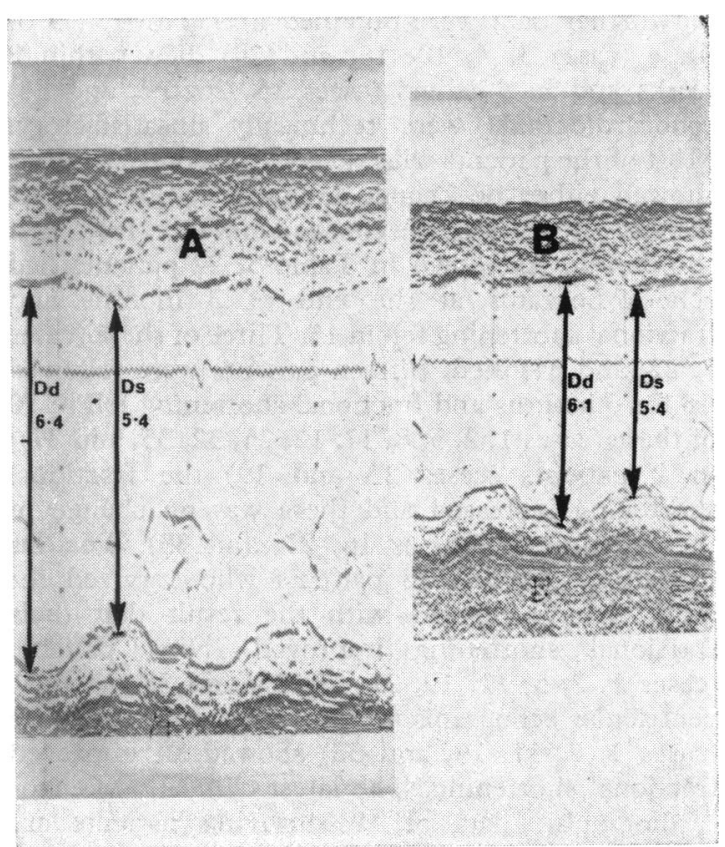

Fig. 2 Left ventricular echograms of case 6 before therapy $(A)$ and 3 weeks later $(B)$.

8-weeks therapy with thyroxine did not cure his fatigue. A peripheral blood test showed a low haemoglobin level and he was referred for further investigations.

On admission to hospital he was found to be in frank congestive cardiac failure (Table 3). His echocardiogram showed poor left ventricular function 
(Table 1). The peripheral blood film showed agranular neutrophils and some neutrophils with Pelga-Hüet abnormality, which is sometimes seen in preleukaemic states. Bone marrow contained 8 per cent myeloblasts: the erythroid and platelet series were severely reduced.

His heart failure was adequately controlled with digitalis and diuretics. Prednisolone (15 mg/day) was started with the hope that it might improve his anaemia, but he required regular transfusions. He has been able to keep his full-time job and his latest echocardiographic findings (Table 5) show a slight reduction in the intraventricular dimensions but the Fs remains low at $\mathbf{0} \cdot 16$. His present haematological picture is that of smouldering leukaemia with a marrow blast count of 25 per cent.

\section{CASE 16}

This 26-year-old man was admitted with a 3-month history of breathlessness, tiredness, and swelling in the neck. He had hepatosplenomegaly and his chest $x$-ray appearances suggested hilar adenopathy. A cervical gland biopsy confirmed the diagnosis of Hodgkin's disease. As the investigations were in progress he developed left ventricular failure with orthopnoea, gallop rhythm, and pulmonary oedema. Non-specific $T$ wave changes were seen in the right praecordial leads and his echocardiogram showed

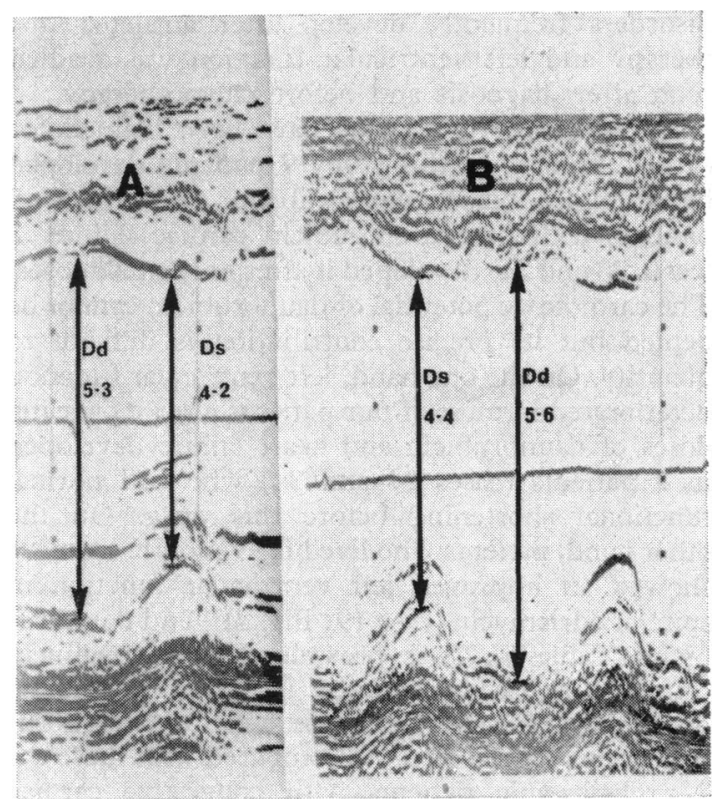

Fig. 3 Left ventricular echograms of case 16. The intraventricular dimensions are abnormal before chemotherapy $(A)$, and have increased further 2 months later $(B)$. depressed left ventricular function (Fig. 3A). His dyspnoea improved with diuretics, but 2 months later he developed congestive cardiac failure after 2 courses of quadruple chemotherapy (nitrogen mustard, vinblastine, procarbazine, and prednisolone). His left ventricular echogram showed a further increase in the intraventricular dimensions (Fig. 3B).

His heart failure became worse in spite of the treatment: he developed jaundice and septicaemia and died. Permission for necropsy was refused.

\section{CASE 19}

A 25-year-old man was referred with an 8-day history of tiredness and frontal headaches. He had generalised lymphadenopathy. A diagnosis of acute lymphoblastic leukaemia was made and he was started on intensive chemotherapy (vincristine, prednisolone, 6-mercaptopurine, and methotrexate). His pretreatment echocardiogram showed poor left ventricular function (Fig. 4A) but he was not in heart failure. A haematological remission was achieved and maintained for $\mathbf{8}$ months during which he received 6 courses of chemotherapy. His left ventricular echogram showed slight improvement in Fs 0.223 months after the remission.

Nine months later his leukaemia relapsed and he was given adriamycin $120 \mathrm{mg}$. A month later, his echocardiogram showed further improvement in left ventricular function with an Fs of 0.29 (Fig. 4B). No further remission could be achieved and he died with septicaemic shock.

\section{CASE 28}

This 30-year-old man with acute myeloblastic leukaemia had no evidence of heart failure on admission and he was given 2 courses of daunorubicin $(200 \mathrm{mg})$ and cytosine arabinoside. Ten days after the second course he became acutely breathless. A third sound gallop was heard and inspiratory crackles were heard over his lung fields. His echocardiogram showed an increase in Ds but a fall in $\mathrm{Dd}$ and consequently a poor Fs (Table 4). He was given digitalis and diuretics but his progress was rapidly downhill and he died. Necropsy showed grossly congested lungs, dilated left ventricle, and haemorrhages in the transverse colon. There were no leukaemic deposits in the heart. The coronary arteries showed slight atheromatous changes but no occlusion.

\section{Discussion}

This study shows that about half the patients in the leukaemia-lymphoma group had depressed left ventricular function before cytotoxic therapy. The 


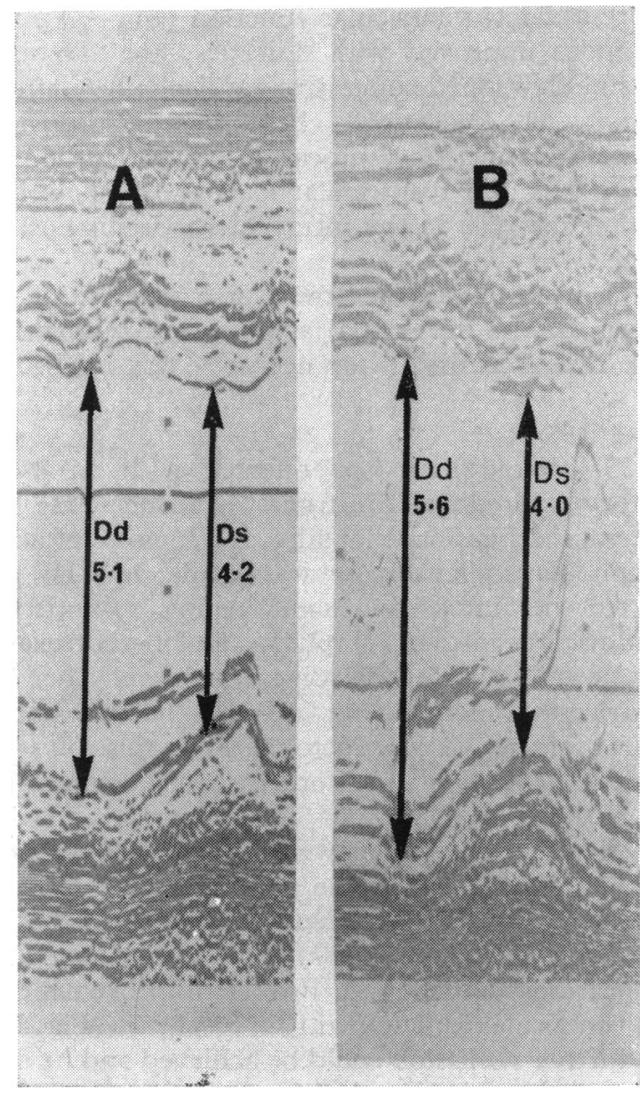

Fig. 4 Left ventricular echograms of case 19. A, before therapy; $B, 9$ months later. Left ventricular function improved (reduction in Ds) 9 months after the diagnosis in spite of cytotoxic therapy including adriamycin.

end-systolic dimension (Ds) in these patients was significantly $(P<0.001)$ greater than in the normal group (Table 2). Left ventricular dysfunction was diagnosed when functional shortening, which is an echocardiographic estimate of systolic shortening of the left ventricular minor axis, was below $0 \cdot 26$. This depends on the intraventricular end-systolic dimension (Ds) and the question arises as to how reliable is this dimension as an index of left ventricular function?

Various workers have shown a highly significant correlation between echocardiographic Ds and the left ventricular minor axis as seen in angiography (Fortuin et al., 1971; Gibson, 1973; Meyer et al., 1975). Shortening of the minor axis accounts for about 80 per cent of the stroke volume (Gault et al., 1968; Hood and Rolett, 1969; Sandler and Ghista, 1969), which makes this dimension an important index of left ventricular function. Functional shortening is a good estimate of the contractile performance of the left ventricle (Fortuin et al., 1972) and a strong correlation has been observed between functional shortening as estimated by echocardiography and by biplane angiography (Cooper et al., 1972; Quinones et al., 1974; Meyer et al., 1975).

The left ventricular dysfunction in leukaemic patients was not caused by anaemia since there was no relation between their haemoglobin level and functional shortening (Table 1). The anaemic group showed better left ventricular function than the normal group as shown by their higher mean Fs (Table 2). This vigorous left ventricular contractility in anaemic patients could have been caused by a combination of low peripheral resistance (Graettinger et al., 1963), low blood viscosity (Mendlowitz, 1948; Richardson and Guyton, 1959), increased diastolic stretch caused by circulatory overload (Sharpey-Schafer, 1944), and tachycardia with the associated increased sympathetic activity. It is, therefore, significant that in spite of the anaemia, leukaemic patients have poor left ventricular function.

Leukaemic patients are prone to infections and develop multiple electrolyte disturbances (Mir and Delamore, 1975; Mir et al., 1975) which may impair left ventricular function. However, these disorders frequently develop after antileukaemic therapy and left ventricular function was studied soon after diagnosis and before chemotherapy.

Anthracycline antibiotics have been blamed for cardiac failure. In this study 7 patients developed heart failure before daunorubicin, and of the 5 patients with post-daunorubicin cardiac failure, 2 (cases 28 and 36) developed it after only small doses. The cardiotoxic potential of daunorubicin cannot be denied but its precise contribution is difficult to quantify. On the one hand, left ventricular function deteriorated in most of our patients after increasing doses of daunorubicin and heart failure developed in 2 patients (cases 28 and 34) who had normal functional shortening before this drug. On the other hand, patients who lived for 9 months or more showed an improved left ventricular function in spite of adriamycin (case 19; Fig. 4B) and daunorubicin (Table 5). It is possible that daunorubicin causes progressive damage in these myopathic hearts since all the 5 patients with post-daunorubicin heart failure died. As compared with these the 3 preleukaemic patients with congestive cardiac failure, who did not receive daunorubicin, survived.

The depressed left ventricular function is not caused by the leukaemic process in the heart since necropsy failed to show leukaemic infiltration of the 
myocardium in 4 patients who died in heart failure.

The results of this study suggest that left ventricular dysfunction in leukaemic patients is unrelated to anthracycline antibiotics. Heart failure is common and, in most cases, unrelated to chemotherapy. The reason why it is not diagnosed frequently is probably because, in these patients, the final illness is complicated by septicaemia and haemorrhage; heart failure can be easily overshadowed, and even when recognised probably considered to be unimportant. Sequential echocardiographic studies have shown that the cardiomyopathy is not reversible though the echocardiographic size of the left ventricle is reduced, with some improvement in patients who live longer than 9 months (Tables 1 and 6).

The cause of the left ventricular dysfunction is not clear. Well-developed congestive cardiomyopathy was present in 3 preleukaemic patients who apparently had the haematological abnormalities for a long period. This suggests that there may be a circulating cardiotoxic factor which after a prolonged contact with the heart produces cardiomyopathy. Experimental studies in our laboratory have shown that extract from the leukaemic primitive cells has a negative inotropic effect on the isolated rabbit heart (Mir et al., 1976). At present there is no evidence that a negative inotropic factor released from the leukaemic blast cells is causally related to leukaemic cardiomyopathy but the possibility suggests an experimental approach to the problem.

I am grateful to Dr I. W. Delamore, Physician in Charge, Department of Clinical Haematology, for allowing me to study the patients under his care, and to Drs E. G. Wade, G. Howitt, and D. J. Rowlands for their help and advice.

\section{References}

Bernard, J., Jacquillat, C., and Boiron, M. (1967). Essai de traitement des leucémies aigües lymphoblastiques et myéloblastiques par un antibiotique nouveau: la rubidomycine (13-057RP). Etude de 61 observations. Presse Médicale, 75, 951-955.

Bonadonna, G., and Monfardini, S. (1969). Cardiac toxicity of daunorubicin. Lancet, $1,837$.

Cooper, R. H., O'Rourke, R. A., Karliner, J. S., Peterson, K. L., and Leopold, G. R. (1972). Comparison of ultrasound and cineangiographic measurements of the mean rate of circumferential fibre shortening in man. Circulation, 46, 914-923.

Feigenbaum, H. (1975). Echocardiographic examination of the left ventricle. Circulation, 51, 1-7.

Fortuin, N. J., Hood, W. P., Jr., and Craige, E. C. (1972).
Evaluation of left ventricular function by echocardiography. Circulation, 46, 26-35.

Fortuin, N. J., Hood, W. P., Jr., Sherman, M. F., and Craige, E. C. (1971). Determination of left ventricular volumes by ultrasound. Circulation, 44, 575-584.

Gault, J. H., Ross, J. Jr., and Braunwald, E. (1968). Contractile state of the left ventricle in man. Circulation Research, 22, 451-463.

Gibson, D. G. (1973). Estimation of left ventricular size by echocardiography. British Heart fournal, 35, 128-134.

Graettinger, J. S., Parsons, R. L., and Campbell, J. A. (1963). A correlation of clinical and haemodynamic studies in patients with mild and severe anemia with and without congestive failure. Annals of Internal Medicine, 58, 617-626.

Halazun, J. F., Wagner, H. R., Gaeta, J. F., and Sinks, L. F. (1974). Daunorubicin cardiactoxicity in children with acute lymphocytic leukemia. Cancer (Philadelphia), 33, 545-554.

Hood, W. P., Jr., and Rolett, E. L. (1969). Patterns of contraction in the human left ventricle (abstract). Circulation, 40, Suppl. III, 109.

Linman, J. W., and Saarni, M. I. (1974). The preleukemic syndrome. Seminars in Hematology, I, 93-100.

Malpas, J. S., and Scott, R. B. (1968). Rubidomycin in acute leukaemia in adults. British Medical fournal, 3, 227-229.

Marmont, A. M., Damasio, E., and Rossi, F. (1969). Cardiac toxicity of daunorubicin, Lancet, 1, 837-838.

Mendlowitz, M. (1948). The effect of anemia and polycythemia on digital intravascular blood visocity. Fournal of Clinical Investigation, 27, 565-571.

Meyer, R. A., Stockert, J., and Kaplan, S. (1975). Echographic determination of left ventricular volumes in pediatric patients. Circulation, 51, 297-303.

Mir, M. A., Bobinski, H., Delamore, I. W., and Wade, E. G. (1976). An experimental investigation into the aetiology of non-infiltrative cardiomyopathy in acute myeloid leukaemia (abstract). Clinical Science and Molecular Medicine, 51, 20p.

Mir, M. A., Brabin, B., Tang, O. T., Leyland, M. J., and Delamore, I. W. (1975). Hypokalaemia in acute myeloid leukaemia. Annals of Internal Medicine, 82, 54-57.

Mir, M. A., and Delamore, I. W. (1974). Hyponatraemia syndrome in acute myeloid leukaemia. British Medical fournal, 1, 52-55.

Quinones, M. A., Gaasch, W. H., and Alexander, J. K. (1974). Echocardiographic assessment of left ventricular function with special reference to normalized velocities. Circulation, 50, 42-51.

Richardson, T. Q., and Guyton, A. C. (1959). Effects of polycythemia and anemia on cardiac output and other circulatory factors. American fournal of Physiology, 197, 1167-1170.

Sandler, H., and Ghista, D. N. (1969). Mechanical and dynamic implications of dimensional measurement of the left ventricle. Federation Proceedings, 28, 1344-1350.

Sharpey-Schafer, E. P. (1944). Cardiac output in severe anaemia. Clinical Science, 5, 125-132.

Tan, C., Tasaka, H., Yu, K. P., Murphy, M. L., and Karnofsky, D. A. (1967). Daunomycin an antitumour antibiotic in the treatment of neoplastic disease. Clinical evaluation with special reference to childhood leukemia. Cancer (Philadelphia), 20, 333-353.

Requests for reprints to Dr M. A. Mir, C2, Department of Medicine, University Hospital of Wales, Heath Park, Cardiff CF4 4XW. 